\title{
Caras y Caretas por dentro
}

\section{El conflicto obrero de 1916 en los talleres del semanario}

\section{Caras y Caretas Inside}

The workers' conflict of 1916 in the factory of the weekly

\section{María Fabiola Di Mare}

fdimare@gmail.com

https://orcid.org/0000-0003-1995-8203

Consejo Nacional de Investigaciones Científicas y Técnicas (CONICET)

Centro de Estudios en Historia / Comunicación / Periodismo / Medios (CEHICOPEME)

Facultad de Periodismo y Comunicación Social

Universidad Nacional de La Plata | Argentina

\section{Resumen}

Caras y Caretas fue una de las primeras empresas periodísticas en formato magazine orientada a un público de masas en la Argentina. En este artículo, la autora analiza los discursos icónicos y textuales de las columnas editoriales publicadas en los aniversarios del semanario en 1916 y en 1917, en relación con el tratamiento construido por la publicación en torno a la huelga que en 1916 tuvo lugar en sus propios talleres. Entre los resultados obtenidos, se identifica el alineamiento de la revista con actores ligados al conservadurismo y la reacción en contra de la agitación obrera del momento.

Palabras clave

Caras y Caretas, huelgas obreras, discurso, editoriales

\section{Abstract}

Caras y Caretas was one of the first journalistic companies in magazine format aimed at a mass audience in Argentina. In this article, the authoress analyzes the iconic and textual discourses of the editorial columns published on the weekly's anniversaries in 1916 and 1917, in relation to the treatment constructed by the publication around the strike that took place in their factory in 1916. Among the results obtained, the alignment of the magazine with actors linked to conservatism and the reaction against the labor agitation of the moment was identified.

Keywords

Caras y Caretas, workers strikes, speech, editorials 


\section{Caras y Caretas por dentro \\ El conflicto obrero de 1916 en los talleres del semanario}

Por María Fabiola Di Mare

Caras y Caretas (1898-1939) fue pionera en cuanto a revistas populares y comerciales en la Argentina. Tuvo su origen en el contexto de las ideas del romanticismo y el positivismo desarrolladas en la prensa de la segunda mitad del siglo XIX (Halperín Donghi, 1980, 1985). El nacimiento de la publicación obedeció a la decisiva afluencia migratoria europea en el territorio argentino. En efecto, el fundador de Caras y Caretas (en adelante, $\mathrm{CyC}$ ) fue Eustaquio Pellicer, periodista y escritor español nacido en Burgos, en 1859, quien inmigró a Montevideo a la edad de 27 años. María Virginia Díaz Juárez (2018) refiere que al arribar a la capital uruguaya fundó la revista Pellicerina. Posteriormente, en 1890, fundó CyC junto con el caricaturista alemán Charles Schütz, y el periodista y escritor argentino Arturo Giménez. La idea de Pellicer era crear una revista humorística, pero este proyecto inicial duró poco. En 1892, se trasladó a Buenos Aires, invitado por su amigo Bartolomé Mitre y Vedia, hijo mayor de Bartolomé Mitre, fundador del diario La Nación.

Unos años después de arribar a la capital de la Argentina, Pellicer decidió refundar CyC, y le solicitó a Bartolomé Mitre y Vedia que fuese su director. Geraldine Rogers (2008) enfatiza las susceptibilidades que había generado en Buenos Aires la guerra de independencia en Cuba contra la dominación española, con lo cual resultaba inconveniente que un oriundo de España fuese el responsable de la publicación. Mitre y Vedia aceptó la dirección, pero renunció antes de que el primer número fuera puesto en circulación. La primera tapa, fechada el 8 de octubre de 1898, contiene una carta mediante la cual este último se disculpa por no poder asumir el compromiso de dirigir el naciente proyecto editorial. En ese momento, tomó la dirección «Fray Mocho», José S. Álvarez, otro reconocido escritor y periodista que venía de trabajar en el diario La Nación.

Un dato interesante para entender el mecenazgo de los Mitre hacia la revista es que su primera sede fue una casona en la calle San Martín 284 de la ciudad de Buenos Aires, donde Mitre y Vedia tenía su oficina como «traductor público, remates y comisiones». 
Antes de cumplir un año, la empresa se trasladó a otro sitio, en Maipú esquina Corrientes, y en septiembre de 1900 pasó a la calle Bolívar al 578. Conviene señalar la referencia hacia «Bartolito» en su época inicial, específicamente, en una nota en la cual el semanario destacó:

«La enfermedad de Bartolito» [...] Para Caras y Caretas esta no era la perspectiva de una desgracia así como se quiera, sino la amenaza de un verdadero golpe físico; porque fue el bizarro espíritu de Bartolito quien dio a esta empresa el más brillante impulso inicial, fue el prestigio de su nombre el primer traje de gala que vistió este periódico (Ojeda \& Moyano, 2015, p. 25).

Lo anterior sugiere los estrechos vínculos entre CyC, el diario La Nación y la familia Mitre, que auspició y que apoyó decididamente al semanario, en especial durante sus primeros años. De hecho, son abundantes las coincidencias ideológicas entre la revista y el diario, algunas de las cuales se profundizan en apartados subsiguientes de este estudio.

CyC tuvo como principal propósito ser una revista popular y de actualidad, que introdujera las diversas corrientes de ideas de otros lugares del mundo en el Río de la Plata. Se diferenció del resto de las publicaciones periódicas que circulaban en el país por no estar vinculada con partidos políticos o corrientes ideológicas.; y se destacó porque pagaba por las colaboraciones, tanto de textos como de fotografías, particularidad que le brindó un lugar relevante en el proceso de profesionalización de los reporteros, los artistas gráficos y los escritores (Díaz, 2019).

En ese marco, el semanario pretendió dirigirse, ya no a los seguidores de una corriente política o a una reducida élite, sino a los ciudadanos cautivos del espectáculo cotidiano en pleno desarrollo. Peter Fritzsche (2008, p. 29) refiere que fueron las publicaciones periódicas de inicios del siglo Xx las que establecieron una relación entre la ciudad textual y la ciudad de cemento o real. En lo particular, la circulación de CyC se convirtió en un acontecimiento que evidenció la modernización cultural del momento. El semanario se dirigió a un público amplio, para el cual construyó una visión de los acontecimientos cotidianos, con énfasis en el paisaje de la ciudad de Buenos Aires y de otras ciudades del país que comenzaban a transformar su fisonomía.

CyC mantuvo un enfoque literario y de actualidad que se ajustaba al subtítulo que formó parte de la portada durante sus primeros años: «Seminario festivo, literario, artístico y de actualidades». Gracias a los adelantos técnicos de la época, la prensa renovó durante 
aquellos años su planteo visual y, precisamente en este aspecto, $\mathrm{CyC}$ se destacó de forma particular. Su notoriedad se basó en el color, las caricaturas, las fotografías y la profusión de avisos comerciales que incluyó en sus páginas desde el primer ejemplar, publicado en 1898.

El semanario atrajo un número importante de lectores mediante un repertorio que capturaba la atención como moda, actualidad, literatura popular, cuentos, novelas, noticias, anuncios publicitarios, ofertas, espectáculos teatrales, graduaciones, tradiciones religiosas, despedidas de solteros, banquetes y reuniones sociales, accidentes automovilísticos, huelgas obreras, crímenes, es decir, temas que transparentaban la vida cotidiana y a la gente corriente.

Puede decirse que hasta 1904 se desarrolló una primera etapa en CyC. A partir de este año, la muerte de Álvarez y el alejamiento de Pellicer provocaron cambios en la dirección que profundizaron la impronta empresarial y comercial, lo que se evidenció en el aumento notable de su volumen, si bien mantuvo la misma proporción de páginas publicitarias y de contenido. Para ilustrar lo anterior, un ejemplar de enero de 1904 tenía $60 \%$ de contenido y $40 \%$ de publicidad, con un promedio de 75 páginas por número. En enero de 1916, se observa un porcentaje similar en la superficie redaccional y publicitaria pero con ediciones que superan las 100 páginas cada semana. ${ }^{1}$

Otro elemento de importancia que realza el valor de CyC para la modernización de la prensa nacional se relaciona con el desarrollo del fotoperiodismo; la publicación pasó de tener entre 10 y 15 fotografías por número, en 1898, a más de 100, en 1910 (Szir, 2004). Durante la época estudiada, se constató que la tendencia hacia la reproducción fotográfica se mantuvo e, incluso, fue en aumento. Por caso, en una edición de octubre de 1916 se contabilizaron en un solo número 139 fotografías; al año siguiente, una edición del mismo mes superó las 200 fotografías, sin tomar en cuenta las caricaturas, los dibujos artísticos y las ilustraciones.

A partir de 1916, CyC hizo más notable su carácter nacionalista, que apostaba por el progreso, el orden, la paz y el trabajo como motores de crecimiento de la industria nacional y del bienestar colectivo. La apuesta visual y tipográfica de la publicación muestra su orientación hacia los valores inherentes a la ideología liberal del progreso y una impronta conservadora ligada al catolicismo.

En octubre de 1923, al cumplir veinticinco años de salida ininterrumpida, la revista se jactó de tener una tirada semanal de $\mathbf{1 5 4 . 4 1 0}$ ejemplares, con una circulación que incluía 
no solo a países vecinos como Brasil, sino también a Europa y a Estados Unidos. ${ }^{2}$ Esta particularidad le permitió manejar en el país un precio bajo, de 20 centavos, lo que por ese entonces era el equivalente a un atado de cigarrillos, y que sostuvo desde 1899 hasta 1939, lo que le posibilitó aumentar de manera significativa el número de lectores, incrementar sus páginas y, también, contar con abundante publicidad.

\section{Caras y Caretas «por dentro»}

Como se afirmó con anterioridad, una de las principales características de CyC fue el carácter de publicación comercial desde su concepción y puesta en circulación en 1898, pero, también, de actor político (Borrat, 1989). Hasta 1901, la publicación tenía como objetivo lucrar y ejercer oposición. ${ }^{3}$ En la etapa posterior a 1905, bajo la dirección de Carlos Correa Luna, CyC acentuó su cariz de empresa comunicacional e independiente, que persigue, además del beneficio crematístico, ejercer influencia en el proceso de toma de decisiones del sistema político.

La etapa inicial es la más abordada por los estudios sobre el semanario. Se conoce que después de la muerte de Álvarez (1903) y del alejamiento de Pellicer (1904), ocupó la dirección de la revista Correa Luna, quien era parte del entorno de confianza de Bartolomé Mitre en la Junta de Historia y Numismática Americana, a la que había sido incorporado a petición de este último (Ojeda \& Moyano, 2015, p. 27 ).

Pese a que hay elementos para vincular la empresa CyC con la familia Mitre y con el diario La Nación, la época posterior a 1916 no ha sido abordada en profundidad por las investigaciones sobre la revista. Ese año inició el primer gobierno elegido sin fraude en la Argentina, el del radical Hipólito Yrigoyen. Esto representó el triunfo de una larga confrontación cívica y armada en contra del régimen conservador y oligárquico, así como el fin de las prácticas electorales fraudulentas para mantener el poder (Botana, 1977/1998; Falcón \& Monserrat, 2000; Rock, 2010).

Solo a partir de lo que la publicación incluye, excluye y jerarquiza, se pueden dilucidar aspectos sobre su ideología y sobre su posición respecto de los conflictos en este momento (Borrat, 1989). Además, a través de sus repertorios temáticos, se la puede asociar con ciertos grupos y actores, a los fines de reconstruir un mapa sobre sus intereses y sus vinculaciones empresariales. 
Los aniversarios son fechas propicias para que un periódico o una revista se representen frente a sus lectores. Los editoriales permiten examinar la posición doctrinaria del medio en función de la construcción periodística y la interpretación que realiza sobre los hechos de la actualidad, lo que incluye la perspectiva de los actores políticos frente a una coyuntura determinada (Díaz \& Giménez, 2019). Entre los fines primordiales, en el editorial

[...] se define un punto de vista, se ayuda al público a formar una opinión acerca de determinado acontecimiento, se analiza y se interpreta la noticia, se relaciona al suceso específico con otros igualmente importantes para situarlos en un determinado contexto histórico y, después, precisar su trascendencia; y, por último, se establecen juicios de valor que propicien actitudes positivas frente a los problemas que afectan a la comunidad (González Reyna, 1999, p. 66).

En términos lingüísticos, un editorial es un enunciado. En efecto, todo discurso es un enunciado, bien sea primario o secundario (Bajtín, [1979] 2012). Los primeros tienen una naturaleza más sencilla, una frase, una oración, un aviso oficial. Los segundos están compuestos por géneros o por discursos de naturaleza ideológica, dentro de los cuales pueden incluirse la novela, el cuento o los discursos de naturaleza diversa como los científicos o los periodísticos, según su función (Bajtín, [1979] 2012). Dentro de esto, debe entenderse que el sujeto hablador o el sujeto de la enunciación piensa en un oyente que debe comprender el mensaje. Por lo general, se asume que el oyente es pasivo, pero en realidad su comprensión es activa, ya que el sujeto de la enunciación «no espera una comprensión pasiva, que tan sólo reproduzca su idea en la cabeza ajena, sino que quiere una contestación, consentimiento, participación, objeción, cumplimento, etc.» (Bajtín, [1979] 2012, p. 379). Es decir, quien enuncia espera una respuesta, una complicidad de su oyente en la comprensión de ese discurso y, eventualmente, una acción al respecto. Esta noción no debe descuidarse en los discursos de CyC que se analizan.

\section{La huelga en los talleres}

Cuando el primer gobierno radical comenzó su mandato, en 1916, llevaba dos años de desarrollo «La Gran Guerra», que después de 1945 se denominó Primera Guerra Mundial. El conflictivo escenario internacional repercutió sobre la economía argentina y en los sectores laborales, lo que incluyó, por supuesto, a los trabajadores de la prensa. Dado que 
CyC era una empresa periodística y que, como tal, uno de sus objetivos era la rentabilidad económica, la situación no le resultó ajena. Era crucial para la publicación que no se redujera de manera significativa su masa de lectores porque esto, a su vez, podía hacer peligrar la obtención de rédito mediante los avisos comerciales. Este esquema de negocio es lo que además garantiza su independencia como medio en la construcción y en la representación de la actualidad.

A partir de 1916, nuevamente emergió con fuerza la organización gremial para luchar contra el atraso reivindicativo que generó la crisis económica iniciada en 1914, alentada por el proceso democratizador que abrió la llegada de la UCR al poder. El incremento en las demandas sindicales también afectó a las empresas periodísticas y, entre ellas, a CyC, que en el primer año del gobierno de Yrigoyen experimentó una paralización en sus talleres. Este conflicto pareció haber amenazado la circulación de la publicación. El 26 de agosto de 1916, en una de las páginas dedicada a notas necrológicas y a eventos sociales, el semanario difundió una nota en la cual se disculpaba con los lectores: «A nuestros lectores. Debido a la huelga de una parte del personal de nuestros talleres gráficos, el público sabrá disculpar las deficiencias que encuentre en este número y que trataremos de subsanar en adelante» ( СуС, 26/o8/1916, p. 53). Se trató de un mensaje breve, ubicado en el cuadrante inferior de la página, que podría pasar desapercibido para cualquier lector distraído o para quienes estuviesen más atentos a las secciones especiales, las páginas de color, los comentarios o las caricaturas.

La revista no ofreció mayores detalles sobre el hecho ni sobre las causas de esta huelga, aunque el panorama económico y social del país permite suponer que los motivos eran salariales. Como consecuencia de la Gran Guerra, la economía argentina sufrió el impacto de la disminución del comercio internacional, lo que repercutió en una regresividad distributiva que empeoró las condiciones de vida de los trabajadores. En este escenario, se combinaron dos factores: el desempleo y la inflación (Gerchunoff, 2016). Para 1916, el desempleo rondaba el $17,7 \% .^{4}$

Como indica Juan Suriano (2017), el mundo del trabajo se vio seriamente afectado por el conflicto bélico, en especial porque el país ya arrastraba el fracaso de la cosecha de granos del año anterior y la disminución en la entrada de capitales extranjeros debido a las restricciones monetarias impuestas por Europa, que provocaron la caída de $10 \%$ del Producto Interno Bruto (PIB). La crisis provocó el congelamiento de los salarios y el incremento en el precio de los artículos de consumo; entre 1914 y 1918, los alimentos 
subieron 50\%, los alquileres se incrementaron $15 \%$ y la vestimenta aumentó 300\%. El salario real experimentó una caída de 30\% durante los años de la guerra. De tal modo que las circunstancias de los trabajadores para ese momento eran críticas y esto pudo tener relación con las causas de la huelga en los talleres de CyC.

\section{«Al público»}

Luego de la publicación de dicho escueto aviso, en agosto de 1916, se puede conjeturar que la empresa había controlado o desbaratado el conflicto. Esto también se puede deducir por la poca importancia que le otorgó al conflicto, al no difundirlo en una página de opinión, de entretenimiento o en una columna editorial. CyC no tuvo intención de omitir el problema laboral, pero le otorgó un tratamiento secundario. No obstante, casi un mes después, el 23 de septiembre, se volvieron a tener noticias sobre el conflicto gremial mediante una columna editorial titulada «Al público» (núm. 938, p. 3), firmada por la dirección, en la cual se hacía un descargo sobre los acontecimientos que circundan al reclamo de los trabajadores de sus talleres.

Este editorial expresa la valoración como empresa, su posición y una estructura argumental que intentaba contradecir las razones del conflicto gremial ocurrido ese año. Otro elemento de interés es la ubicación de dicha página que, al aparecer tercera, prácticamente «abre» la edición. Este emplazamiento indica que al voltear la tapa, es la primera que se encuentra el lector. Gráficamente, no es una página que capte la atención, puesto que no tiene ningún tipo de imagen, icono, fotografía o caricatura; de allí que pueda afirmarse que se trató de un tratamiento inusual, dada las características visuales de la superficie redaccional y publicitaria del semanario.

En ese sentido, no parece ser una sección para el público habitual, acostumbrado al predominio de la imagen. Es una página seria, incluso aburrida para el lector que busca ocio y entretenimiento; destaca por su simpleza y por la falta de elaboración o de cuidado visual. No se trata de un mensaje dirigido hacia quienes buscan las imágenes o las secciones de entretenimiento, y no se entiende como una zona que invite a la lectura (Vilches, 1987). Su ubicación, sin ningún tipo de elemento icónico llamativo, hará que solo los más interesados lean la columna. 
Desde hace algún tiempo, CARAS Y CARETAS viene siendo objeto de una campaña tan tenaz como injusta, procurando vanamente con ella restarle el favor que el público siempre le ha dispensado. Resolvimos callar, escudándonos en nuestra insospechable conducta; pero hoy, teniendo en cuenta la persistencia de los ataques y que nuestro silencio podría interpretarse torcidamente, decidimos contestar para que se sepa la verdad de lo ocurrido.

Caras y Caretas -empresa argentina por los elementos que la constituyen y por su espíritu- se formó en 1898 , contribuyendo con todos sus medios a la cultura general del país y al desarrollo de las artes gráficas, que propios y extraños han reconocido sin regateos.

Inspirada siempre en los mismos propósitos, en noviembre de 1911 estableció sus talleres gráficos con los elementos más modernos que pudo adquirir para mejorar sus trabajos (CyC, 23/o9/1916, p. 3).

Debe entenderse que nada de lo abordado en este discurso era fruto del azar. La empresa se posicionó desde un lugar de enunciación, con todo su prestigio o su capital cultural acumulado. Desde allí parte la argumentación mediante la cual intentaba deslegitimar las medidas adoptadas por los huelguistas dentro de sus talleres. Fue una respuesta institucional y autolaudatoria que la empresa periodística asumió como un acto de defensa ante los ataques y los vilipendios que estaba recibiendo, a causa del conflicto obrero en un espacio neurálgico para la empresa, que se había consolidado y modernizado casi veinte años después de la fundación de $\mathrm{CyC}$, y sin el cual la revista no podía circular. En tal sentido, mediante la columna no se buscaba explicar los motivos de la huelga sino refutar a sus actores, en especial, a la Federación Gráfica Bonaerense (FGB), ${ }^{5}$ el gremio de los obreros gráficos.

Desde dicha fecha hasta hoy, no se ha dejado de atender NI UNA SOLA VEZ las reclamaciones presentadas por los obreros a la Dirección, aún aquellas que no tenían relación con los talleres; y apelamos al testimonio de los mismos obreros, seguros que no ha de presentarse NI UNO SOLO a negar esta afirmación.

El 2 de agosto último, la Dirección, sin tener el menor antecedente y desconociendo en absoluto las causas que justificaran tal actitud, recibió una nota de la Federación Gráfica Bonaerense comunicándole que debía expulsar al jefe del taller de grabados. La dirección quedó sorprendida de tan injustificado procedimiento, pues ni siquiera se había tenido en ella la elemental atención de darle a conocer ni directa ni indirectamente los motivos de tal determinación. 
Y como este hecho, por lo insólito, pudiera ponerse en duda, invocamos al testimonio de los mismos obreros que han intervenido en el conflicto, en la seguridad de que no habrá NI UNO SOLO capaz de negar estos hechos.

¿Qué razones han podido existir para que, si SIEMPRE han sido atendidas las reclamaciones, en este caso se prescindiera de la Dirección, haciéndole conocer la queja por la Nota de la Federación Obrera? Lo ignoramos ( $\mathrm{CyC}$, 23/09/1916, p. 3).

En este alegato, la revista se presentaba como si hubiera estado a disposición de los trabajadores y ellos, en lugar de reconocer esa cualidad, hubieran decidido dirimir el conflicto con el gremio, interpretándose a este último como extraño al personal y a la empresa. En efecto, es extraño a la empresa, pero aquí CyC se presenta como un todo, patrones y obreros que no podían dividirse por la intervención de un ente externo, la FGB. De este modo, la intención se orientó a demostrar la preocupación hacia los trabajadores y, en todo caso, la suerte de «traición» cometida por estos al acudir al gremio.

CyC cuestionaba que el conflicto no se hubiera canalizado directamente con la dirección, sino que se hubiera acudido de inmediato al gremio, lo cual para la empresa resultaba un menoscabo de su autoridad, al tiempo que le servía para ubicarse en el lugar de víctima ante su lectorado. Esto pone en evidencia la proporción del conflicto, que trascendió el espacio de la empresa y se transformó en una huelga obrera declarada por el sindicato como actor central. Por las exclusiones que hace la revista en cuanto a la explicación de los hechos, se puede inferir que el jefe del área de grabados estaría teniendo un comportamiento inapropiado con los obreros, dado que la empresa no desmiente ni minimiza la justificación del gremio.

Como indica Roberto Marafioti (1998), un enunciado tiene una compleja trama de significaciones; es un producto y un registro de la enunciación que lo provocó. De tal modo que toda alocución es explícita o implícitamente una alocución que postula un alocutario. En este caso, se interpela al público lector, pero también a los propios obreros de los talleres de la empresa. El texto intenta comunicar un principio de racionalidad y un sentido organizacional que debe primar en una empresa en la cual hay una estructura para dirimir o para canalizar mensajes desde abajo hacia arriba, o desde los mandos medios a los superiores. Aquí estaría la «falta» o la «traición» de los obreros. 
Se trata, en este caso, de un discurso que apela a la razón pero también a la emocionalidad. Esta emocionalidad se funda en una lógica racional sobre cómo deben ser las cosas, en lo que Marafioti (1998) denomina la «disociación de nociones» y a la que define como «una transformación provocada siempre por el deseo de suprimir una incompatibilidad nacida de la confrontación de una tesis, ya se trate de normas, hechos o verdades»(p. 205). A su vez, permite elaborar estructuras persuasivas más sólidas, como la «depreciación de lo que fue aceptado como valor hasta un determinado momento y su progresivo reemplazo por otra concepción a la que se le asigna un valor original» (Marafioti, 1998, p. 206).

En ese sentido, se trata de persuadir al lectorado acerca de la injusticia con la que actuaron los trabajadores, quienes acudieron directamente al gremio para mediar en el conflicto, en lugar de transmitir sus inconformidades a la dirección de la empresa. Según esta perspectiva, frente a un reclamo de carácter gremial, lo natural no es que los obreros acudan al sindicato que los representa sino que expongan las razones de su disconformidad al propietario de la empresa.

Asimismo, hay un principio argumentativo de verdad en la retórica de este texto, para lo cual se usan signos lingüísticos, como el empleo de la mayúscula sostenida en determinadas frases y en adverbios como «siempre», «ni una sola vez», «ni uno solo». Trata de enfatizarse y de darle fuerza a lo que se afirma para otorgarle un sentido de verdad, de fidelidad con la realidad y, a través de ello, para persuadir a los lectores. Esto, a su vez, puede tomarse como una tautología, dado el carácter de demostración formal, casi irrebatible, reduccionista, «una verdad incuestionable pero vacía», como indica Marafioti (1998, p. 201). Posterior a esto, el autor de la columna analizada toma argumentos cuasilógicos para cuestionar la posición de los huelguistas y del gremio en cuestión.

Pero aún hay más: de las investigaciones que posteriormente se hicieron, resultó que al incidente entre el jefe del taller de grabados y los operarios se le había tratado de dar una gravedad que no tenía, quedando demostrado poco después por la falta de eco que encontró entre los mismos operarios.

El 11 de agosto se realizó en la Federación Gráfica el escrutinio del referéndum hecho en nuestros talleres, para decidir la actitud a seguir ante el conflicto. El escrutinio dio el resultado siguiente:

A favor de los obreros de la huelga...................................41

En contra........................................................12 
Se abstuvieron

Total. $\ldots 72$

Es decir, que la huelga se resolvió por 41 votos sobre los 193 operarios que trabajan en Caras y Caretas.

Naturalmente, este resultado dio sus frutos, y a los pocos días la huelga quedó terminada, como lo demuestran las siguientes cifras:

Operarios que trabajan en Caras y Caretas. .193

De estos mismos operarios trabajan actualmente. .134

Operarios nuevos. 33

Operarios que no han vuelto al trabajo. .59

Y como estas cifras, que no tienen réplica, han tratado de ser desvirtuadas, y no es cosa de estar todos los días aburriendo al público con rectificaciones, avisamos que todos los datos de cuanto afirmamos están a la disposición de todo aquel que quiera salir de dudas (CyC, 23/09/1916, p. 3).

En este apartado del texto, la intención es convertir los argumentos en irrefutables a partir de la construcción de argumentos cuasi-lógicos, que «se presentan como comparables a razonamientos formales, lógicos o matemáticos» (Marafioti, 1998, p. 200). La persuasión cobra fuerza al poner datos estadísticos o numéricos sobre los obreros adeptos a la huelga, los contrarios y los que se abstuvieron en el conflicto. Lo mismo ocurre con las cifras acerca de los operarios que empleaba la empresa, los que trabajaban en ese momento y los que se mantenían en conflicto. Esto último permite suponer que la huelga o el conflicto obrero continuaban, pues sus motivos no habían sido zanjados.

El discurso emplea el razonamiento numérico como prueba irrefutable de la poca adhesión de obreros a la huelga y de la escasa cantidad de operarios que se mantenían paralizados. Esto intentaba minimizar el impacto numérico de los obreros «conflictivos», así como la naturaleza del conflicto cuyo fondo no queda en evidencia, puesto que es tratado como un asunto que no debió tomar las proporciones alcanzadas.

\section{«La expedición de Caras y Caretas»}

Nada más se volvió a saber sobre este asunto en la revista, pero sus repercusiones parecen haber llegado lejos, en tanto que el 7 de octubre de 1916, al cumplirse el XVIII 
aniversario, el semanario volvió sobre la huelga de agosto, a través de una construcción informativa, icónica y textual titulada «La expedición de Caras y Caretas» (núm. 940, pp. 43-44). Este mensaje manifestaba a su lectorado la institucionalidad y la organización interna de la empresa periodística, con un estilo apologético y admonitorio. Se trata de un discurso opinático y enunciativo, que puede calificarse de editorial ya que está «vinculado temáticamente con la información más importante del día» (González Reyna, 1999, p. 66); en este caso, el aniversario de la publicación.

El conflicto ocurrido en agosto no solo había amenazado la circulación de $\mathrm{CyC}$ sino su credibilidad como empresa y, con ello, la fidelidad de sus lectores, que de manera esperaban cada número con los contenidos de preferencia. La interrupción pondría en riesgo su interés crematístico, así como el pacto de lectura establecido con su público (Chartier, 1995). Esto se soporta en las afirmaciones de la propia empresa sobre la propagación de rumores y sobre la existencia de una campaña de descalificación en su contra, de acuerdo con los argumentos expresados en la columna editorial del 7 de octubre. El texto inicia con una interpelación directa a los lectores y a quienes con su trabajo hacían posible que el semanario se publicara cada semana.

Los que sueñan con hacer una revista, no sospechan, quizá, que aún en el caso de tener éxito, el problema es dificilísimo. Salvada la primera dificultad, que es hacerla interesante y que guste al público, cosa en verdad costosa, a juzgar por el número de revistas que no han podido pasar del número uno, se presentan una serie de inconvenientes que en la mayoría de los casos no se han previsto al presupuestar sus gastos (CyC, 07/10/1916, p. 43).

La empresa buscaba transmitir a su público que la puesta en circulación de $\mathrm{CyC}$ era una verdadera proeza, en medio de un escenario complejo de crisis que le había impedido sobrevivir a otros medios. Además de que suponía un desafío económico, tecnológico y humano fundar un medio de comunicación y mantenerlo en el tiempo. En la época que abordamos, sostener una revista por tantos años era prácticamente una excepción a la regla, ya que, tal como se indicaba en la propia $\mathrm{CyC}$, muchas publicaciones fenecían al poco tiempo de iniciada su circulación. A esto se agregaba la dificultad de insertarse con éxito dentro del campo periodístico y de lectura masiva del momento.

Este aniversario fue una oportunidad para que $\mathrm{CyC}$ se reivindicase como una de las revistas que contaba con mayor tiempo de circulación en el país, y que había logrado sortear obstáculos y desafíos para llegar a sus lectores. 
Para un gran número de personas, hacer una revista se reduce a tener imprenta que la imprima, grabador que haga los clisés y casa que fíe papel... Claro que todo esto se lo imaginan contando con el éxito, y puestos a soñar, ya ven su administración asaltada por los canillitas en demanda de números, al encargado de las suscripciones haciendo fajas a destajo para dar cumplimiento a los suscriptores y al público, al soberano lector, yendo desesperado de kiosco en kiosco sin poder hacerse de un ejemplar por haberse agotado la edición.

Pero aceptando que el sueño se convierta en realidad, y el éxito les acompañe en su empresa, tengan por seguro que entonces es cuando surgen las verdaderas dificultades.

Calculando que la tirada llegase a cien mil o más miles de ejemplares, como nosotros tenemos que producir semanalmente, se encontrarán, que la imprenta no da abasto.

Y que no pasan de los dedos de la mano los que en Buenos Aires puedan comprometerse a un trabajo semejante; que debido a la gran cantidad de copias, hay que hacer clisés cuádruples, o estereotiparlos, cosa que demanda obreros especiales; que la encuadernación resulta otro problema, pues debe hacerse ese trabajo en pocas horas y las máquinas de encuadernar corrientes no han previsto esas enormes tiradas; y que la mayoría de los subscriptores recibirían sus números con retraso, porque escribir miles de direcciones es trabajo de días (CyC, o7/10/1916, p. 43).

La empresa ponía de relieve a sus trabajadores, obreros especializados sin los cuales era imposible que circulase y que cumpliese con sus objetivos comerciales. En este editorial, se intentaba mostrar la solidez institucional y organizacional en cuanto al encadenamiento de los procesos técnicos internos para lograr que el semanario salga a la calle, llegue a los kioskos o a los canillitas y, de ahí, a las manos de los lectores. No es casual que esta columna se dedicara, precisamente, a brindar loas al área que vivió una situación de conflicto dentro de la empresa: los talleres gráficos donde se ejecutan las labores mecánicas de impresión para la confección de los ejemplares del semanario.

En la misma columna, se denomina a los ingenieros de los talleres como «hombres de pensamiento»y se los muestra como «dispuestos a resolver problemas», presentándolos como un par antagónico respecto de los pocos huelguistas (Díaz, 2007, p. 109). A propósito, destaca la tecnología de avanzada con la que contaba la empresa al referir con orgullo la posesión de «una máquina que permite hacer dos mil direcciones por hora 
y prácticas encuadernadoras que dan salida a miles de ejemplares por hora, y con guillotinas "revólver" que cortan simultáneamente los tres márgenes de la revista» $(\mathrm{CyC}$, 07/10/1916, pp. 43-44). Se entiende este discurso como autoapologético tanto de la propia empresa periodística como de sus trabajadores, sin los cuales sería imposible que la revista circulase en distintas partes del país y a nivel internacional, por ejemplo en Brasil, en Europa y en Estados Unidos.

CyC quería comunicar a sus lectores que la empresa periodística estaba sólida, que continuaba en el tiempo pese a las adversidades y que sus trabajadores seguían prestos a brindar lo mejor de su genio y su esfuerzo para que la revista no dejara de circular. Que su continuidad no estaba bajo amenaza ni en cuestión, aun frente al convulso escenario que atravesaba la Argentina.

\section{El relato en imágenes}

La columna sobre el aniversario está acompañada por fotografías sobre los trabajos en los talleres [Figura 1]. En correspondencia con Roland Barthes (1986), se puede afirmar que la reproducción fotográfica es un campo visual o expresivo que demuestra una realidad. Es un discurso denotativo, tiene un carácter de verdad, de fidelidad con la realidad. Pero, al mismo tiempo, encierra una connotación porque tiene significados, ideología. Philipe Dubois (1983/1986) pone en cuestión la idea mimética que se tiene de la fotografía como el resultado objetivo de la neutralidad de un aparato, la cámara fotográfica. Si bien la imagen fotográfica, y más aún la fotografía periodística, transmite una escena de lo real, un aparente lenguaje natural de una realidad, el recorte, la perspectiva y la profundidad producen efectos y sentidos. «La caja oscura fotográfica no es un agente reproductor neutro sino una máquina que produce efectos deliberados. Es, lo mismo que la lengua, un asunto de convención y un instrumento de análisis y de interpretación de lo real» (Dubois, 1983/1986, pp. 37-38).

Existe una tradición crítica sobre la fotografía y sobre las imágenes desde la escuela de Frankfurt. Se puede recordar a Walter Benjamin (1936), con su conocido ensayo La obra de arte en la época de su reproductibilidad técnica. Para este autor, la imagen fotográfica, en tanto objeto reproducido en masa, cambiaba el estatuto de la obra de arte. La imagen se consideraba desprovista del aura que tiene la obra artística y, por esa razón, era subvalorada al ser un artículo para las masas. En la prensa, sin embargo, la imagen tiene otros propósitos. Como indica Barthes (1986), la fotografía de prensa es un discurso 
denotativo porque encierra una realidad objetiva, fiel a los acontecimientos, aunque también contiene en sí misma una connotación que generalmente es histórica y cultural. Asimismo, Román Gubern (1987) y Susan Sontag (2006) refieren que en esa época las fotografías se adaptaban a la necesidad de aportar evidencias en el apogeo del positivismo. Las fotografías muestran una realidad y son una prueba empírica de los hechos; permiten demostrar lo que se escucha o se lee.

La imagen es el recurso primordial utilizado por СyC para narrar y para sostener una idea de verdad y de fidelidad respecto de los hechos que comunicaba. De hecho, como se indicó en apartados anteriores, la imagen fotográfica era un aspecto privilegiado en la revista, que tenía vinculación con el positivismo de la época donde lo comprobable empíricamente adquiría un valor significativo. Sandra Szir (2011) refiere que esta resultó esencial en diversos campos científicos como la medicina, la psicología, la criminología y otras, al tiempo que cobraba auge en el ámbito de los consumos culturales, con la prensa y las publicidades. Como refiere esta autora, $\mathrm{CyC}$ formó parte de la creación de una producción y de un consumo visual masivo, así como de la transformación del lector en espectador.

La fotografía también es una señal del pacto de lectura que el semanario hizo con sus lectores para mostrarles el presente y la actualidad en su forma más exacta posible. A propósito, Rogers (2008) refiere que CyC también se destacó por la preponderancia que le otorgó a las imágenes y a la fotografía de actualidad. Las técnicas gráficas empleadas por la revista impactaron en el mercado periodístico nacional, e incluso en los diarios La Prensa y La Nación, que a partir de 1904 incorporaron el fotograbado con máquina rotativa para publicar fotos en sus ediciones diarias (Rogers, 2008, p. 99). Valga mencionar que el modo en el que circularon los equipos de oficios gráficos entre $\mathrm{CyC}$ y La Nación fue descripto por Alejandra Ojeda (2018), quien refiere la presencia de fotograbados impresos en rotativa desde el año 1900 en ambas publicaciones periódicas. De acuerdo con esta autora, el propio diario reconoció, el 1 de enero de 1904, la difusión cómoda, cotidiana y de mejor calidad de fotografías.

En el semanario, los acontecimientos políticos y las huelgas se narran en imágenes porque estas posibilitan otorgar un carácter de verosimilitud a los hechos. Además, como indica Lorenzo Vilches (1987), la fotografía resulta valiosa y atractiva para una publicación vinculada al ocio y a la lectura de entretenimiento y de actualidad por el carácter llamativo que tiene en la página y en el espacio donde se ubique. 
Las imágenes describen fielmente unas acciones dotadas de significación, ya que cada persona está representada realizando una labor. Hay una connotación en este discurso que trata de normar las conductas hacia el trabajo, el sacrificio y la virtud. Se trata de caracterizar las tipologías de la ciudadanía ejemplar. Se evidencia una finalidad formativa, edificante y moralizante, cuyo objetivo era crear conciencia en la ciudadanía. La publicación se ajusta al patrón de modernización cultural y urbana para modelar pautas acorde con los valores de orden, de disciplina y de normalización de la sociedad, en el marco de un panorama que se tornaba cada vez más conflictivo en el ámbito laboral y social.

Las fotografías se seleccionaron para que el público viese a los trabajadores de forma activa, trabajando en la impresión y en la reproducción de las páginas, en la transcripción de las direcciones de los suscriptores, en el guillotinado, en la encuadernación y en la costura de los pliegos, en el empaquetado y en la obtención del producto final, los paquetes de ejemplares.

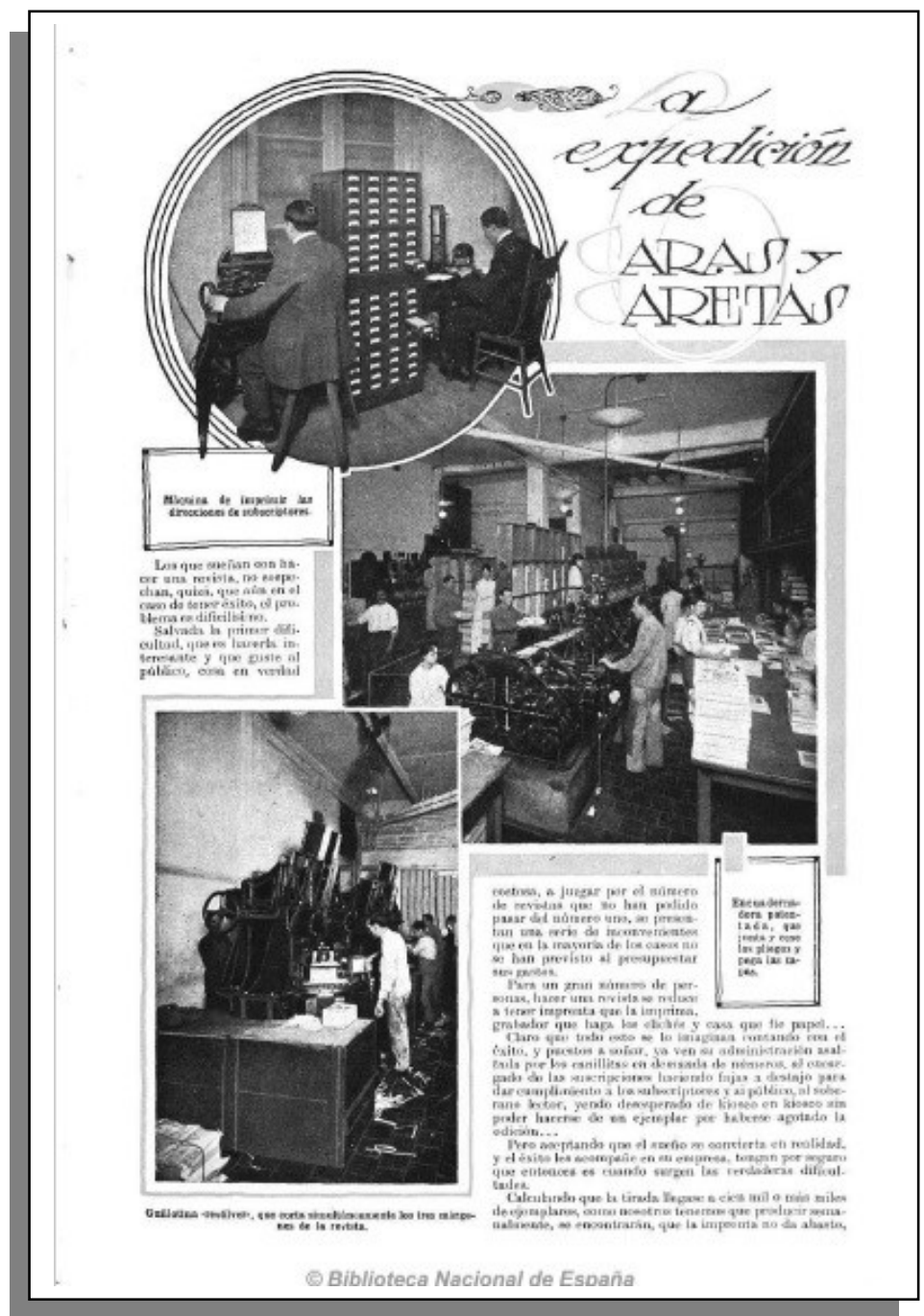


En ese sentido, la publicación mostraba una realidad objetiva: el trabajo activo de sus empleados. Muchos parecen capturados sin que se percaten de ello, de espalda, sentados, concentrados en su labor, sin poses ni artificios. El interés no era buscar el esteticismo en el encuadre fotográfico, sino expresar las acciones de los sujetos representados. Son fotografías tomadas en plena jornada de trabajo y esto tiene una significación en una época de agitación a nivel social y laboral. Se buscaba comunicar la vida de la revista, la «Caras y Caretas por dentro», en la que se trabajaba de manera constante.

Estas fotografías son una estructura informativa que da lugar a la interpretación porque producen sentidos en un contexto específico. Hay un sentimiento de época que está detrás de estos mensajes comunicacionales: la Gran Guerra o Primera Guerra Mundial, los levantamientos revolucionarios obreristas y populares en distintas partes del mundo, principalmente en Europa. Argentina, aparentemente, ya había transitado su época de mayor agitación obrera, de 1890 hasta las celebraciones del Centenario en 1910, según la lectura de Suriano (2005) y de Migueláñez Martínez (2010). No obstante, el «fantasma» de la subversión seguía orbitando en la atmósfera y por eso era necesario propiciar la paz con los sectores laborales, instar al orden, al trabajo y convocar a una suerte de conciliación obrerista que detuviese la amenaza de una revuelta social.

«Paz, orden y trabajo»

Un medio masivo y popular como $\mathrm{CyC}$, incorpora visiones o perspectivas de mundo (Fritzsche, 2008). Además, su posición política como medio de comunicación frente a los conflictos obreros, como indica Borrat (1989), viene dada por las inclusiones, las exclusiones y las jerarquizaciones. $\mathrm{CyC}$ no dejó de mostrar las huelgas obreras de diversos sectores económicos, pero estableció distinciones en el tratamiento de estas medidas de fuerza. El conflicto dentro de sus propios talleres fue omitido y poco se conoce de este en otros periódicos de la época. En contraposición, mostraba al público una perspectiva de empresa casi monolítica, integrada por obreros que se esforzaban y ponían todo su ingenio para que la revista circulara.

El semanario mantuvo un discurso coherente acerca de las huelgas obreras, que se puso de manifiesto en distintos momentos, como en los sucesos de la Semana Trágica de 1919, en la represión hacia los trabajadores de las estancias ovejeras en la Patagonia, en 1922 (Di Mare, 2018a), o en las protestas de los trabajadores ferroviarios (Di Mare, 2018b). Un ejemplo del manejo sobre temas vinculados con los obreros fue el ejemplar del 
3 de mayo de 1919, cuya portada se tituló «Paz, orden y trabajo» (núm. 1.074). Estas ideas no encontraron mejor momento que el 1 de Mayo para ser exhibidas. Ese año, que se caracterizó por la efervescencia en los conflictos laborales, comenzó con una de las huelgas más sangrientas vividas en el país, la Semana Trágica de enero de 1919, mote incorporado por la propia $\mathrm{CyC}$ al hacer referencia a los luctuosos sucesos acaecidos en los talleres de la firma Vasena (Di Mare, 2018c). Por eso, no es una casualidad que en la conmemoración del día de los trabajadores se enfatizaran los valores de la paz, el orden y la nacionalidad.

Aquí, en plena paz, el proletariado argentino que vive en una tierra generosa donde sus aspiraciones encuentran favorable ambiente festeja hoy el día simbólico de sus ideales.

Los hombres de buena voluntad que militan en otros partidos y sostienen otros principios, acompañan al obrero espiritualmente en este día. Todos reconocen y saben conceder justo valor a los obreros, a los que solo viven del trabajo para extraer los escondidos metales, fabricar las máquinas y los alimentos, cultivar la tierra y hacerla fructífera. Sin el trabajo anónimo y colectivo, la vida y la civilización no existirían. Sin el deseo de mejoramiento, sin el ansia de bienestar, el hombre nunca lograría vencer en la lucha contra tantos obstáculos. Suprema ley de la existencia es, pues, la del trabajo; pocos se eximen de ella, porque pesa sobre todos como igual justicia. Pocos, muy pocos, no festejarán, pública e íntimamente, el 1º de Mayo (CyC, 03/05/1919, p. 40).

El discurso destaca que todas las ideologías consideran el 1 de Mayo un día festivo, contrarrestando, de este modo, la propaganda anarquista que lo ubicaba como una fecha «clasista» o de «lucha». Otro elemento de interés es que posiciona la emblemática fecha bajo la órbita espiritual o religiosa, lo que le permite exaltar el trabajo como valor para lograr la superación personal, el bienestar o la idea de "progreso» individual y colectivo.

Lo señalado coincide con el planteo de Inés Yujnovsky (2004), quien divide la relación de $\mathrm{CyC}$ con el mundo obrero en dos momentos, uno de afinidad y otro de aversión. Hasta 1919, el tratamiento y, en particular, el uso de la fotografía otorgaron amplia visibilidad a la organización obrera, las asambleas laborales, los movimientos huelguísticos, las paralizaciones y las actividades de reanudación; fue una época de cierta simpatía hacia los trabajadores. A partir de 1919, con la Semana Trágica, la publicación 
cambió su opinión sobre las huelgas y las coberturas se centraron en calificar a los huelguistas de «ácratas», «minorías subversivas», «exaltados», «plaga», encuadrándolos cual suerte de «enfermedad del cuerpo social» y legitimando, así, la represión hacia los obreros.

En ese contexto, en la columna editorial del 1 de Mayo de 1919 se emplea el recurso de «par antagónico» (Díaz, 2007), que contrapone a los violentos de enero con los obreros pacíficos que tiene la Argentina en el campo y en la industria. Otro elemento de interés es que la fecha permite visibilizar a las familias. No solo los textos sino también las imágenes muestran a los obreros y a las obreras, hombres y mujeres, así como también a los niños, en un tratamiento que evidencia el horizonte ideológico que la revista quiere inculcar en sus lectores: trabajo, familia, paz, orden. Como indica Fernando Devoto (1999), en esta época, el matrimonio y la familia se instituyeron y se normativizaron como la base de la estabilidad social. Esto, además, aporta un sentido religioso que atraviesa el tema obrero en la revista, como en el apartado siguiente:

Y, seguramente, en muchos hogares humildes, habrá mujeres y hombres que no puedan permitirse el relativo lujo de festejar descansadamente el día del obrero. ¿Que en esa forzada laboriosidad les acompañe el recuerdo de sus compañeros y de los hombres de corazón altruista, siempre propicio a sentir como suya las desgracias del prójimo! (CyC, 03/05/1919, pp. 40).

En este texto, hay una idea cristiana de sacrificio, de desinterés por el otro y de solidaridad. A partir de estos enunciados temáticos (Steimberg, 1993), la religión católica se introduce en el tema obrero. En esa época, los conservadores auspiciaban poner a los obreros bajo la órbita del catolicismo a través de los Círculos Obreros Católicos (McGee, 2003), por medio de los cuales podían mantener el control de la cuestión obrera y encauzarla hacia el orden y la paz deseada. Esta misma idea atraviesa, en buena medida, los discursos en torno a las huelgas y los conflictos, como fue el caso de la huelga experimentada en sus propios talleres.

\section{«Los que nacieron con Caras y Caretas»}

La exaltación del trabajo como un valor propio de una sociedad civilizada es un tema recurrente en $\mathrm{CyC}$ que en el aniversario de 1917 se dedicó también a este tema, pero desde una perspectiva que le otorgó mayor relevancia al público. La empresa aprovechó 
su $19^{\circ}$ aniversario para brindar loas a sus fieles lectores, con un texto que se ubica en el cruce entre editorial y crónica, ya que se propone desde un «nosotros» como empresa. Fue una sección de dos páginas intitulada «Los que nacieron con Caras y Caretas» (núm. 992, p. 28). Para la ocasión, construyó una sección dedicada a los lectores. El mensaje, mediante la apelación a la metáfora organicista o biológica (Díaz \& Giménez, 2017), establece una analogía entre la publicación y el ser humano que atraviesa distintas etapas: nacimiento, crecimiento, adultez y madurez.

Diez y nueve años cumplimos el 8 de octubre; no nos toca decir si los hemos aprovechado mal o bien; el público lo dice todos los días. A él, la ardua sentencia... Más, con nosotros nacieron, hace diez y nueve años, infantes que ahora son hombres, algo así como un símbolo vivo de nuestra propia existencia. En la vida humana, los primeros diez y nueve años pasan rápido; en los de una revista son quizá los más lentos. Ellos y nosotros los hemos vivido juntos; hemos recorrido juntos el mismo camino, en el tiempo.

Hoy, ellos sirven a la patria, cumpliendo su deber, que también ha sido el nuestro. Al entrevistarnos, con algunos de aquellos a quienes cupo nacer el mismo día en que apareció nuestra revista, fuimos de sorpresa en sorpresa. Aquellos mozos fuertes que se presentaban a nuestros ojos eran la manifestación más elocuente del camino andado. Nos imaginamos los sacrificios y pruebas porque pasaron en su edad infantil, acechados por todos los peligros, para encontrarse en la edad adulta fuertes y robustos.

Así es nuestra revista, después de las rudas pruebas porque pasó en los primeros tiempos, es hoy un organismo, dentro del periodismo nacional, sano y vigoroso, que en todo momento disfrutó de los favores del público (CyC, o6/10/1917, p. 28).

Esta columna por el aniversario, que tiene todas las características de editorial, nuevamente exalta las virtudes de la revista y su solidez como empresa. Esta vez, empero, permite interpretar la representación de un grupo etario entre los lectores. Se establece un parangón biologicista entre la revista y quienes, entre sus consumidores, tienen la misma edad, presentándolos como organismos vivos, que nacen y crecen paralelamente. Al mismo tiempo, representa al público como hombres comunes, citadinos, trabajadores de profesiones liberales u oficios manuales; los otrora niños que crecieron leyendo $\mathrm{CyC}$. Otro elemento que destaca es la mención al sacrificio como 
condición para lograr la prosperidad. Además, está presente el concepto de patria, que no estuvo en el aniversario anterior pero que aquí se rescata para equiparar el trabajo con la construcción de lo nacional.

De esta manera, establece una familiaridad con el público al tratar de evidenciar el interés en la narración de sus vidas y sus prácticas cotidianas:

Pero hay algo que hace que consideremos más el pretérito. Los que nacieron a la vida el mismo día que nosotros, dejaron de ser donceles para convertirse en hombres, y cada uno según su capacidad, es un ciudadano del que la patria espera grandes frutos. Todos ellos llevan hoy en la vida su misión, pues son honestos y trabajadores, y han dedicado su inteligencia y energías a un fin práctico.

Nicolás Porreca, gana su vida como electricista. Arturo Follino ha dedicado su inteligencia al comercio y se emplea en venta de sombreros de paja, esperando hacer un brillantísimo negocio en la próxima estación veraniega. Antonio Scales, es músico. Siente pasión por el violín, y le deseamos que en el desempeño de su arte llegue a superar a Kubelik. Luis V. Savigliano es un dactilógrafo de marca, y se gana la vida como empleado [...] Ellos, en forma tangible, ponen de relieve que ya hemos llegado a la edad adulta, que los años no han pasado en vano y, como ellos, tenemos en la sociedad una alta misión que cumplir, la del trabajo (CyC, o6/10/1917, p. 28).

La revista evita el alejamiento con los lectores; por el contrario, los convoca a que se identifiquen a través de una experiencia común. Asimismo, convierte de esta forma a un grupo de hombres en ejemplo modélico para la sociedad, en ciudadanos cuyos comportamientos deben emularse. Interpreta las expectativas y el horizonte cultural de sus lectores porque no solo transmite lo que espera del público, sino lo que piensa que el público cree de sí mismo y de qué forma desea ser reflejado. No se trata de un público especializado ni culto; son hombres de los sectores populares, que se han asimilado a la vida en la ciudad, a los empleos vinculados con las nuevas formas de vida que conlleva la cultura del consumo en ciernes. También destaca que se dedican a tareas muy dispares, lo cual le permite reivindicar que la revista llega a un amplio abanico de lectores.

Para esta empresa comunicacional, la práctica del trabajo es una normativa que regula o que pone límites a las pasiones humanas. A su vez, un tópico que atraviesa los discursos del semanario es el referido al trabajo como sinónimo de patria, de nacionalidad: 
Nuestros colegas saben como nadie la labor que hemos tenido que realizar para llegar al puesto que ocupamos y si siempre hemos contado con la benevolencia del público ha sido porque dentro de nuestra misión hemos sido en todo momento leales con nuestra nacionalidad y parcos en juicios definitivos. Nuestras caricaturas podrán haber sido intencionadas, pero jamás malevolentes. $\mathrm{Y}$ en el orden intelectual, Caras y Caretas siempre fue una casa abierta a toda manifestación de arte [...] (CyC, o6/10/1917, p. 28).

Este editorial , utiliza como principio de autoridad a sus colegas, quienes pueden dar fe del esfuerzo realizado y del acompañamiento del público que le permitieron a $\mathrm{CyC}$ llegar a donde llegó; refiere a las prácticas periodísticas de la propia publicación, al tratamiento que hace de los temas políticos, reconociendo la intencionalidad en destacar temáticas o en canalizar opiniones a través de las caricaturas, un lenguaje icónico y lúdico que predomina en todos sus ejemplares desde que surgió en 1898 y que la distinguen como medio de comunicación. La heterogeneidad o polifonía discursiva que la caracteriza, la lleva a emplear el humor como mecanismo para emprender la crítica y a la vez generar una suerte de orientación ligada al entretenimiento y la familiarización del lector con el texto.

La fotografía, como se indicó anteriormente, es otro modo de apropiación por parte de los lectores, que interpreta sus prácticas de lectura en clave de rapidez, de liviandad y de fidelidad con la realidad. En la columna también hay fotografías que invitan a leer y que contribuyen a dotar de sentido a la narración [Figura 2]. Se denotan los protagonistas, los personajes de la narración en sus puestos de trabajo: el primero, está rodeado de sombreros; el segundo, posa junto al violín; el tercero, escribe a máquina; y el cuarto, se encuentra en plena labor de reparación de una lámpara.

Es necesario señalar, también, lo que esta columna editorial excluye. La revista pudo referirse a personalidades y a figuras literarias, pero optó por limitarse a hacer una breve mención: «Literariamente, hemos contado siempre con la colaboración de las firmas más prestigiosas de nuestro mundo intelectual, aun aquellas de respetable abolengo consagradas por la fama mundial han honrado casi siempre nuestra revista» (СуC, o6/10/1917, p. 28). De este modo, prefirió centrarse en el ciudadano común y en sus lectores habituales.

Otra exclusión destacable es que en esta columna la publicación eligió representar solo a hombres, obviando al público femenino. Este aspecto llama la atención porque, si bien el semanario mantuvo una orientación tradicional en cuanto a temas circunscritos al 
«ámbito de la mujer» (Bellah y otros, 1989, p. 121) como el hogar, la familia, la domesticidad y la belleza, mediante secciones como «La mujer y la casa» o las dedicadas a la moda femenina, también fue una de las pocas publicaciones que destacó su participación en protestas gremiales, como ocurrió con las mujeres involucradas en la huelga de las fosforeras o en la organización de la Gran Huelga Ferroviaria, ambas en 1917 (Di Mare, 2018b).

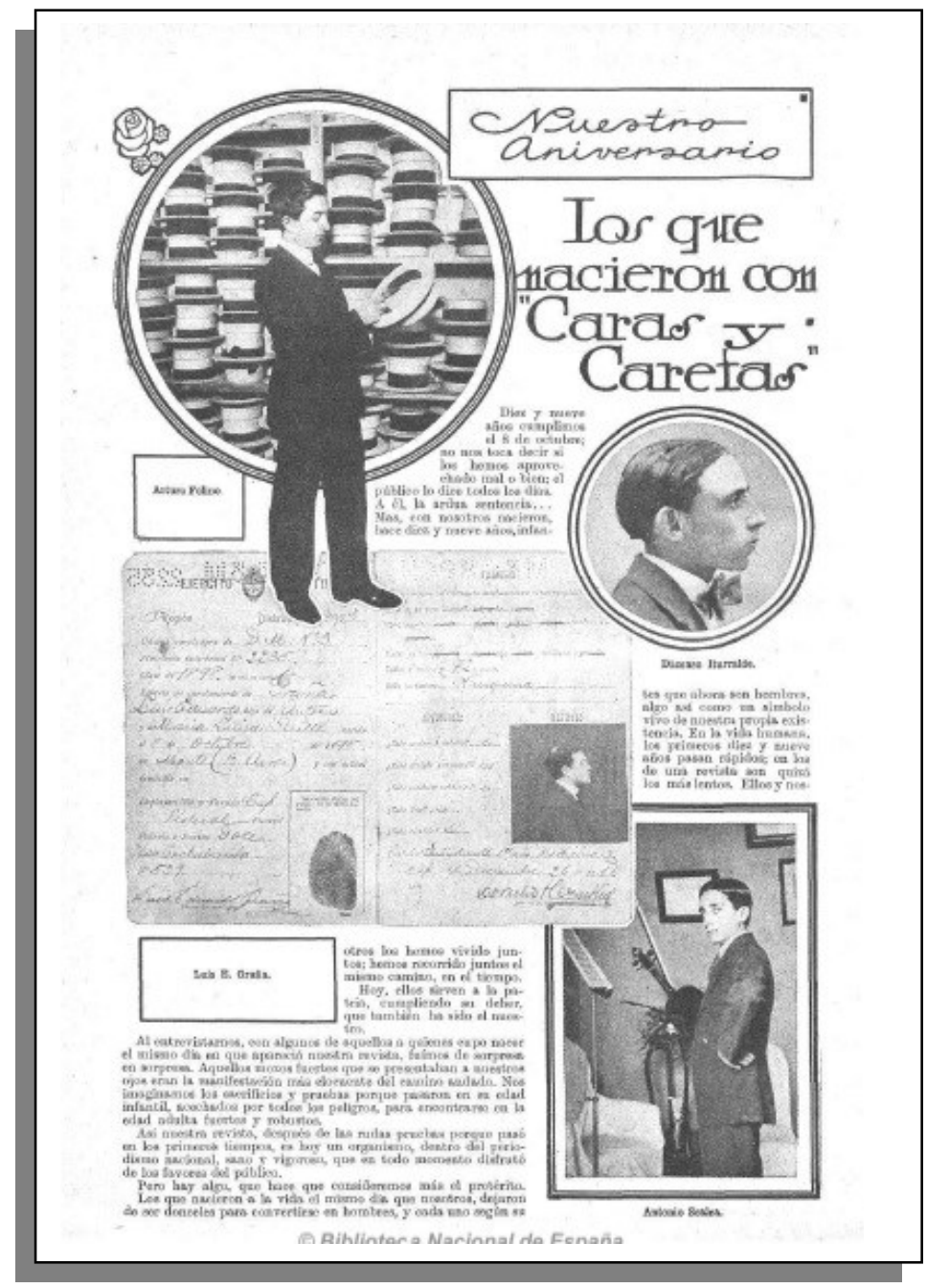

Figura 2. Página aniversario, 6 de octubre de 1917 Fuente: Biblioteca Nacional de España

De igual modo, la publicación difundía en todos sus números fotografías de mujeres que ejercían labores de beneficencia o que realizaban trabajos ligados a la instrucción primaria o la enfermería, que en épocas anteriores eran socialmente reconocidos como femeninos. Sin embargo, el semanario también destacó imágenes de mujeres que irrumpían, cada vez más, en ocupaciones que antes eran exclusivamente masculinas. Esto se observó en las representaciones sobre mujeres obreras, por ejemplo, en la 
inauguración de un restaurante en la calle Esmeralda 486 de la Capital, para uso de obreras ( $\mathrm{CyC}, 01 / 07 / 1916$, p. 50); en las fotografías de mujeres trabajando en una fábrica de aeroplanos, en Estados Unidos (CyC, o6/o7/1918, pp. 97-98); o en el número especial de 1919 dedicado al Primero de Mayo (СyC, 03/05/1919, p. 40).

\section{Reflexiones finales}

El semanario empleó un tratamiento moralizante respecto de los conflictos obreros, frente a los cuales expuso su visión patronal construida desde la perspectiva de una de las más poderosas empresas periodísticas del país, sea desde la magnitud económica soportada en la profusa publicidad con la que contaba, como desde el nivel de credibilidad alcanzado fruto del sólido pacto de lectura construido con su público.

La huelga que afectó a CyC en 1916 se convirtió en un acontecimiento relevante para la publicación, pues actuó como acicate para que pudiera expresar con contundencia discursiva su perspectiva, fundamentada en los valores hegemónicos ligados al orden, al trabajo y a las ideas católicas y nacionalistas en auge en ese momento. En efecto, la medida de fuerza gremial ocurrida dentro de sus propios talleres puso en riesgo la continuidad ininterrumpida de la que tanto se jactaba el semanario. Por ello, además de hacer público el conflicto en sus páginas, se encargó de brindar información soportada en argumentos cuasi-lógicos, así como en la disociación de verdades y al establecimiento de un discurso que orbitó en torno a ideas racionales y emocionales, con el propósito de demostrar la «traición» que, a su criterio, habían cometido los obreros que encabezaron el conflicto dentro de sus talleres.

Asimismo, como demostración del nulo impacto que le produjo aquella huelga, en el aniversario de 1916 empleó todos los recursos textuales e icónicos que tenía al alcance para reafirmar su solidez como organización empresarial. Utilizó el recurso de «par antagónico» para contraponer a los obreros de la empresa que siempre estaban prestos a resolver los problemas con los huelguistas.

CyC cuestionó que el cese de actividades se aprovechase para armar una revuelta dentro de sus instalaciones, apelando al gremio. El hebdomadario entendía que el conflicto dentro de sus talleres debió haberse efectuado por la vía jerárquica de la empresa y no mediante la intervención de la FGB. De hecho, a propósito de otras conmemoraciones 
importantes como el 1 de Mayo, la revista comunicó la idea que manejaba en torno a las huelgas obreras, las cuales eran un motivo aceptable de lucha pero no una justificación para subvertir el statu quo ni para armar una revuelta o para provocar el cese de operaciones en empresas, como ocurrió en sus propios talleres.

De igual forma, se demostró la familiaridad que perseguía la revista con su público mediante especiales como el aniversario de 1917, en el cual, a diferencia del año anterior, se otorgó mayor preponderancia a los lectores masculinos, obviando al lectorado femenino. En esta columna editorial, se destaca el recurso de la metáfora organicista o biológica, en la que se compara al semanario con un organismo humano, que nace, crece y se desarrolla, es decir, que está a la par de sus lectores.

Finalmente, el tratamiento de $\mathrm{CyC}$ en los editoriales aniversarios analizados demuestra su posición dentro del mapa político/comunicacional a partir de 1916, a través de la alineación con actores específicos asociados a la oligarquía y, por ende, a la reacción hacia el gobierno del presidente Hipólito Yrigoyen.

Referencias

Barthes, R. (1986). Lo obvio y lo obtuso. Imágenes, gestos, voces. Barcelona, España: Paidós.

Bajtín, M. (2012) [1979]. Estética de la creación verbal. Ciudad de México, México: Siglo Veintiuno.

Bellah, R. N., Madsen, R., Sullivan, W. M., Swidler, A. y Tipton, S. M. (1989). Hábitos del corazón. Madrid, España: Alianza.

Bill, D. A. (2018). Transformaciones en la industria y luchas de los obreros gráficos en Buenos Aires (1878-1940). En F. Ares (Comp.), En torno a la Imprenta de Buenos Aires (1780-1940) (pp. 247-276). Ciudad Autónoma de Buenos Aires, Argentina: Gobierno de la Ciudad.

Borrat, H. (1989). El periódico, actor político. Barcelona, España: Gustavo Gili.

Botana, N. (1977/1998). El orden conservador. La política argentina entre 1880 y 1916. Ciudad Autónoma de Buenos Aires, Argentina: Sudamericana. 
Chartier, R. (1995). Sociedad y escritura en la edad moderna. Ciudad de México, México: Instituto Mora.

Devoto, F. (1999). Historia de la vida privada en la Argentina. La Argentina plural: 1870-1930. Ciudad Autónoma de Buenos Aires, Argentina: Taurus.

Díaz, C. (2007). Combatiendo la ignorancia aprendida: la prédica jauretcheana en la revista Qué: 1955-1958. La Plata, Argentina: EDULP.

Díaz, C. (2019). El periodismo gráfico del siglo XX. La Plata, Argentina: EPC. Recuperado de https://perio.unlp.edu.ar/wp-content/uploads/2020/o7/PeriodismoGrafico-del-Siglo-XX_digital-al-13-7-DIGITAL.pdf

Díaz Juárez, M. V. (2018). Narrar la historia: la internacionalización de las ideas en las portadas de Puch-Puk-Caras y Caretas (Tesis de doctorado). Madrid, España: Universidad Complutense de Madrid. Recuperado de https://eprints.ucm.es/id/eprint/46421/

Díaz, C. y Giménez, M. (2017). La Nación y el sindicalismo en 1983: la crisis, las huelgas y la democratización. RIHC, Revista Internacional de Historia de la Comunicación, 9(2), 92-117. Recuperado de http://dx.doi.org/10.12795/RiHC.2017.iog.04

Díaz, C. y Giménez, M. (2019). Los editoriales de La Nación en pos de la institucionalidad liberal durante los dos primeros años de Alfonsín. Actas de Periodismo y Comunicación, 4(3). Recuperado de https://perio.unlp.edu.ar/ojs/index.php/actas/article/view/5442

Di Mare, M. F. (2018a). Radicalismo y represión. Un análisis desde el discurso de Caras y Caretas. Actas de Periodismo y Comunicación, 3(3), 1-14. Recuperado de https://perio.unlp.edu.ar/ojs/index.php/actas/article/view/4826

Di Mare, M. F. (2018b). La construcción periodística de Caras y Caretas frente a la Gran Huelga Ferroviaria de 1917. Actas de Periodismo y Comunicación, 4(3), 1-21. Recuperado de https://perio.unlp.edu.ar/ojs/index.php/actas/article/view/5589 Di Mare, M. F. (2018c). La construcción del discurso periodístico de la revista Caras y Caretas frente a la represión de la Semana Trágica de 1919. RIHC, Revista Internacional de Historia de la Comunicación, (10), 243-267. http://dx.doi.org/10.12795/RiHC.2018.110.12 Dubois, P. (1983/1986). El acto de fotografiar. De la representación a la recepción. Ciudad Autónoma de Buenos Aires, Argentina: Paidós. 
Falcón, R. y Monserrat, A. (200o). Estado, empresas, trabajadores y sindicatos. En R. Falcón (Dir.), Democracia, conflicto social y revolución de ideas (1916-1930) (pp. 151-193). Ciudad Autónoma de Buenos Aires, Argentina: Sudamericana.

Fritzsche, P. (2008). Berlín 19oo. Prensa, lectores y vida moderna. Ciudad Autónoma de Buenos Aires, Argentina: Siglo Veintiuno.

Gerchunoff, P. (2016). El eslabón perdido. La economía política de los gobiernos radicales (1916-1930). Ciudad Autónoma de Buenos Aires, Argentina: Edhasa.

González Reyna, S. (1999). Periodismo de opinión y discurso. Ciudad de México, México: Trillas.

Gubern, R. (1987). La mirada opulenta. Exploración de la iconosfera contemporánea. Barcelona, España: Gustavo Gili.

Halperín Donghi, T. (1980). Proyecto y construcción de una nación (Argentina, 1846-1880). Caracas, Venezuela: Biblioteca Ayacucho.

Halperín Donghi, T. (1985). José Hernández y sus mundos. Ciudad Autónoma de Buenos Aires, Argentina: Sudamericana.

Marafioti, R. (1998). Recorridos semiológicos. Signos, enunciación y argumentación. Ciudad Autónoma de Buenos Aires, Argentina: Eudeba.

McGee Deutsch, S. (2003). Contrarrevolución en la Argentina, 1900-1932. La Liga Patriótica Argentina. Bernal, Argentina: Universidad Nacional de Quilmes. Migueláñez Martínez, M. (2010). 1910 y el declive del anarquismo argentino. ¿Hito histórico o historiográfico? Trabajo presentado en el XIV Encuentro de Latinoamericanistas Españoles: 200 años de Iberoamérica (1810-2010). Santiago de Compostela, España. Recuperado de https://halshs.archives-ouvertes.fr/halshso0529699/document

Ojeda, A. (2018). Dibujantes, grabadores y orladores en el diario La Nación: consolidación del oficio entre el campo artístico y los trabajos para la industria (Buenos Aires, 1894-1900). En P. A. Laguna y G. F. Martínez (Eds.), El negocio de la prensa en su historia iberoamericana. Madrid, España: Fragua. 
Ojeda, A. y Moyano, J. (2015). Del Estado al mercado. El periodismo mitrista en la modernización de la prensa argentina (1862-1904). En A. Pineda y F. Gantús, F. (Comps.), Recorridos desde la prensa moderna a la prensa actual. Querétaro, México: Universidad Michoacana de San Nicolás de Hidalgo / Universidad Autónoma de Querétaro.

Rock, D. (2010). El radicalismo argentino. 1890-1930. Ciudad Autónoma de Buenos Aires, Argentina: Amorrortu.

Rogers, G. (2008). Caras y Caretas: cultura, política y espectáculo en los inicios del siglo XX argentino. La Plata, Argentina: Universidad Nacional de La Plata. Recuperado de http://www.memoria.fahce.unlp.edu.ar/library?a=d\&c=libros\&d=Jpm413 Sontag, S. (2006). Sobre la fotografía. Ciudad de México, México: Alfaguara. Steimberg, O. (1993). Semiótica de los medios masivos. El pasaje a los medios de los géneros populares. Ciudad Autónoma de Buenos aires, Argentina: Atuel. Suriano, J. (2005). Auge y caída del anarquismo. Argentina, 1880-1930. Ciudad Autónoma de Buenos Aires, Argentina: Capital Intelectual.

Suriano, J. (2017). La Primera Guerra Mundial, crisis económica y agudización del conflicto obrero en Argentina. Estudios Históricos, 30(60), 93-114. https://doi.org/10.159o/s2178-14942017000100006

Szir, S. (2004). Memoria colectiva y mensaje visual masivo. Experiencia cultural y fotografía en Caras y Caretas. Trabajo presentado en las VI Jornadas de Estudios e Investigaciones, Artes Visuales y Música. Ciudad Autónoma de Buenos Aires, Argentina: Universidad de Buenos Aires. Recuperado de https://www.academia.edu/40273352/Memoria_colectiva_y_mensaje_visual_masivo_ Experiencia_cultural_y_fotograf\%C3\%ADa_en_Caras_y_Caretas

Szir, S. (2011). El semanario popular ilustrado Caras y Caretas y las transformaciones del paisaje cultural de la modernidad. Buenos Aires 1898-1908 (Tesis de doctorado). Recuperado de http://repositorio.filo.uba.ar/handle/filodigital/1886 Taub, E. (2008). Otredad, orientalismo e identidad: nociones sobre la construcción de otro oriental en la revista Caras y Caretas: 1898-1918. Ciudad Autónoma de Buenos Aires, Argentina: Teseo.

Vilches, L. (1987). Teoría de la imagen periodística. Barcelona, España: Paidós. 
Yujnovsky, I. (2004). Una vista panorámica de huelgas, manifestaciones y mítines en Caras y Caretas. Prensa y fotografía a principios del siglo XX en Argentina. América Latina en la Historia Económica, (22), 129-153.

\section{Fuentes analizadas}

Caja Dotal para obreras (1 de julio de 1916). CyC, núm. 926, p. 50.

A nuestros distinguidos lectores (26 de agosto de 1916). CyC, núm. 934, p. 53.

Al público (23 de septiembre de 1916). CyC, núm. 938, p. 3.

La expedición de Caras y Caretas (7 de octubre de 1916). CyC, núm. 940, pp. 43-44.

Nuestro aniversario. Los que nacieron con Caras y Caretas (6 de octubre de 1917).

CyC, núm. 992, p. 28.

La fabricación de aeroplanos en Norteamérica (6 de julio de 1918). CyC, núm. 1.031, pp. $97-98$.

Paz, orden y trabajo (3 de mayo de 1919). CyC, núm. 1.074, portada.

Notas

1 En 1898, la revista contaba con 20 páginas semanales; en 1904, sumaba 80 páginas en cada número; y en 1916, una edición semanal tenía un promedio de 105 páginas.

2 De acuerdo con Emmanuel Taub (2008), el tiraje de la revista llegó a su pico en 1910, con la venta de 201.150 ejemplares en una sola edición.

3 Durante los primeros dos años de publicación, $100 \%$ de las caricaturas de tapa fueron contra el presidente Julio Argentino Roca y su gobierno, con excepción de la presentación, los aniversarios y las festividades (Ojeda \& Moyano, 2015).

4 Ese año, se experimentó un récord en el desempleo respecto de épocas anteriores. Mientras que en 1912 este indicador rondaba el 5,1\%, en 1915 se ubicó en 14,5\% (Gerchunoff, 2016, p. 68).

5 En el país, la primera institución gremial de trabajadores gráficos fue la Sociedad Tipográfica Bonaerense, fundada en 1857. En el siglo XX, esta institución se consolidó y se unieron otras organizaciones laborales del sector, creándose, en mayo de 1907, la Federación Gráfica Bonaerense (Bill, 2018). 